\title{
Performance Analysis for a Card Cleaner Type Separating System of Pepper Harvester
}

\author{
J0, Yeon-Ju
}

Department of Bio-Industrial Machinery Engineering, Chonbuk National University I Laboratory of Agricultural Machinery and Production Systems Design, Division of Bioproduction Environmental Sciences, Department of Agro-environmental Sciences, Faculty of Agriculture, Kyushu University

\section{KANG, Young-Sun}

Research \& Development Institute, Tongyang Moolsan Co. LTD. | Laboratory of Agricultural Machinery and Production Systems Design, Division of Bioproduction Envi-ronmental Sciences, Department of Agro-environmental Sciences, Faculty of Agriculture, Kyushu University

NAM, Ju-Seok

Department of Biosystems Engineering, Kangwon National University | Laboratory of Agricultural Machinery and Production Systems Design, Division of Bioproduction Envi-ronmental Sciences, Department of Agro-environmental Sciences, Faculty of Agriculture, Kyushu University

\section{CHOE, Jung-Seob}

Department of Precision Mechanical Engineering, Kyungpook National University I Laboratory of Agricultural Machinery and Production Systems Design, Division of Bioproduction Envi-ronmental Sciences, Department of Agro-environmental Sciences, Faculty of Agriculture, Kyushu University

他

https://doi.org/10.5109/1911185

出版情報: 九州大学大学院農学研究院紀要. 63 (1)，pp. 103-111，2018-02-27. Faculty of Agriculture, Kyushu University

バージョン：

権利関係 : 


\title{
Performance Analysis for a Card Cleaner Type Separating System of Pepper Harvester
}

\author{
Yeon-Ju JO ${ }^{1}$, Young-Sun KANG ${ }^{2}$, Ju-Seok NAM ${ }^{3}$, Jung-Seob CHOE ${ }^{4}$, Eiji INOUE ${ }^{5}$, \\ Takashi OKAYASU ${ }^{5}$ and Dae-Cheol KIM ${ }^{1,6 *}$
}

\author{
Laboratory of Agricultural Machinery and Production Systems Design, Division of Bioproduction Envi-ronmental Sciences, \\ Department of Agro-environmental Sciences, Faculty of Agriculture, \\ Kyushu University, Fukuoka 812-8581, Japan \\ (Received October 31, 2017 and accepted November 20, 2017)
}

\begin{abstract}
This study conducted a factorial experiment with an experimental bench to analyze the separation performance of a card cleaner type separating system of pepper harvesters. The factors used for this study were the card arrangement (inline and staggered), slope angle $\left(5^{\circ}\right.$ and $\left.15^{\circ}\right)$, and rotational speed $(35,50$, and $65 \mathrm{rpm}$ ) of the card cleaner. The separation efficiency of peppers was influenced by the slope and rotational speed of the card cleaner in both types of card arrangement. In the inline arrangement, the mixing ratio of foreign materials was influenced by slope angle but not influenced by the rotational speed of the card cleaner. In the staggered arrangement, the mixing ratio of foreign materials was influenced by slope angle and the rotational speed of the card cleaner. The high separation efficiency in the staggered arrangement was obtained under the conditions of a slope of $5^{\circ}$ and a rotational speed of $50 \mathrm{rpm}$. However, the mixing ratio of foreign materials was also high in this condition. The high separation efficiency in the inline arrangement was obtained under the conditions of a slope of $15^{\circ}$ and a rotational speed of $50 \mathrm{rpm}$, and the mixing ratio of foreign materials was relatively low in this condition. Thus, the inline arrangement with a slope angle of $15^{\circ}$ was recommended for a separating system of self-propelled pepper harvesters.
\end{abstract}

Key words: pepper harvester, separating system, card cleaner, field cleaning, factorial experiment

\section{INTRODUCTION}

World pepper production in 2012 was estimated to be 31,172,000 metric tons, and pepper production in China took $51 \%$ of the world production with $16,024,000$ metric tons. Pepper production in the United States took $3.4 \%$ of the world production with 1,065,000 metric tons. The United States has increased imports of pepper from Mexico and Peru since NAFTA (North American Free Trade Agreement) was signed in 1994, and pepper production in the US has decreased rapidly due to the intensified price competition. As a result, US market continues to import over $80 \%$ of total consumption from overseas (FAOSTAT, 2012).

In Korea, peppers are essential seasoning and they are cultivated to a large extent. The cultivation area for peppers takes $38 \%$ of total condiment vegetable cultivation area (KOSTAT, 2014). In the pepper farming, har-

1 Department of Bio-Industrial Machinery Engineering, Chonbuk National University, 567 Baekje-daero, Deokjin-gu, Jeonju, Jeollabuk-do, 54896, Republic of Korea

2 Research \& Development Institute, Tongyang Moolsan Co. LTD., Chadong-ro, Useong-myeon, Gongju, Chungcheongnamdo, 32530, Republic of Korea

3 Department of Biosystems Engineering, Kangwon National University, 1 Kangwondaehak-gil, Chuncheon, Gangwon-do, 24341, Republic of Korea

${ }^{4}$ Department of Precision Mechanical Engineering, Kyungpook National University, Gajangdong, Sangju, Republic of Korea

${ }^{5}$ Department of Agro-environmental Science, Faculty of Agriculture, Kyushu University, 6-10-1 Hakozaki Higashi-ku, Fukuoka 812-8581, Japan

${ }^{6}$ Institute for Agricultural Machinery \& ICT Convergence, Chonbuk National University, 567, Baekje-daero, Deokjin-gu, Jeonju-si, Jeollabuk-do, Republic of Korea.

* Corresponding Author (E-mail: dckim12@jbnu.ac.kr) vest labor accounts for $39.2 \%$ of total labor when hand harvest is used, therefore, harvest mechanization is required for labor saving in harvesting peppers (Choi, 2006).

Several companies from China, Israel and USA have been developing self-propelled pepper harvesters which include picking heads, separating parts, conveying parts, and collecting parts to reduce labor and costs. The separating parts of the pepper harvester conveys fruits from the picking heads to the collecting parts while discharging foreign materials such as branches and leaves out of the machine. Optimal design of the separating parts is important because it's a big problem for the pepper harvester that peppers are harvested along with branches and leaves. Without adequate separation process of foreign materials, peppers are deteriorated during the storage and transportation, which affects the sale price (Kong et al., 2013). Thus, many studies on the separation process of foreign materials have been conducted. Marshall (1984) evaluated a trash removal system for various pepper cultivars. The performance of the trash removal system was differed depending on the shape and size of the fruits. Cherry pepper showed the separation ratio of more than $90 \%$ and damage ratio of less than $4.1 \%$. However, large stems and branches were observed after passing through the separation system, therefore, additional process that picking up the remaining foreign materials beside the conveyor was required. Eaton and Wilson (2005) analyzed the separation ratio of the peppers cultivated in New Mexico, USA using a card cleaner type separation system. They found that the separation ratio of peppers was differed depending on the moisture content of the pepper samples. The separation ratio of peppers immediately after harvest 
was $93.5 \%$, but that of peppers far after the harvest season reduced by 70 75\%. Kong et al. (2013) developed a separation device using a star wheel and airflow in China. Considering the average lengths of pepper and branch, spacing of the star wheel was designed to be 180 200 $\mathrm{mm}$, and the distance between the axes was designed to be $180 \sim 200 \mathrm{~mm}$. And an air blower was designed by measuring terminal velocity of peppers and leaves in the device.

Herbon et al. (2006) developed a sorting system using weight difference between pepper and foreign material in the fast-moving belt with velocity difference. The results showed $83.45 \%$ of the separation ratio, but further studies on field test are still needed. Wolf and Alper (1984) developed a machine harvesting system for paprika. The separation device discharged small plant particles such as seeds, leaves, and twigs while transporting fruits. The device consisted of three star wheels rotating in a single direction and a square rubber plate, and it showed $42 \%$ of the separation ratio. They predicted that eight star wheels would improve the performance of the device. Hong et al. (2006) conducted a study with peppers mixed with foreign materials such as leaves and stems in a separating device having a fan, a belt conveyor for discharging peppers, and a foreign material discharge cylinder. Leaves were discharged at wind speeds of 12 to $15 \mathrm{~m} / \mathrm{s}$, and the separation ratio was 95\%. Choi (2006) analyzed the performance of a mechanical harvesting system using pepper cultivar of Wangdaebak, Saengryek No. 211, and Saengryek No. 213. The experimental device consisted of an air blower, an oscillating sieve separator, and a conveyor was manufactured by improving a separation device of a head-feed combine. After examining the terminal air speed, oscillating frequency, and oscillating amplitude of the devices, optimum operation that produced the divided fruit ratio of $68.2 \%$ was observed at a terminal air speed of $6.2 \mathrm{~m} / \mathrm{s}$, an oscillating frequency of $6.9 \mathrm{~Hz}$, an oscillating amplitude of $40 \mathrm{~mm}$, and the diameter and spacing of cleaning fingers of $6 \mathrm{~mm}$ and $29 \mathrm{~mm}$, respectively.

Card cleaner type separation system for pepper harvesters have been widely used because of several advantages such as simple structure, easy manufacturing, and good separation performance. There is, however, not much experimental researches for them, especially for important factors affecting separation performance.

In this study, the factorial experiment was conducted to analyze the separation performance of a card cleaner type separating system of pepper harvesters. The factors used for this study were the card arrangement, slope angle, and rotational speed of the card cleaner. Theses parameters are important in the card cleaner type separating system, but experimental studies for their effects have not been performed. Optimum working conditions were determined through the experiment, and suggestions to improve the separation performance were presented by analyzing the separation performance for each factor.

\section{MATERIALS AND METHODS}

\section{Experimental Device}

Fig. 1 shows the shape of the experimental bench used in this study, and Fig. 2 depicts the specification of the device. Driving part had a $0.4-\mathrm{kW}$ variable speed (VS) motor and an inverter to control the conveying speed of the card cleaner, and the bars in the fifteen axes were driven by a chain and sprocket. Spacers were inserted between the cards to separate the foreign materials such as twigs and leaves from the fruits on the

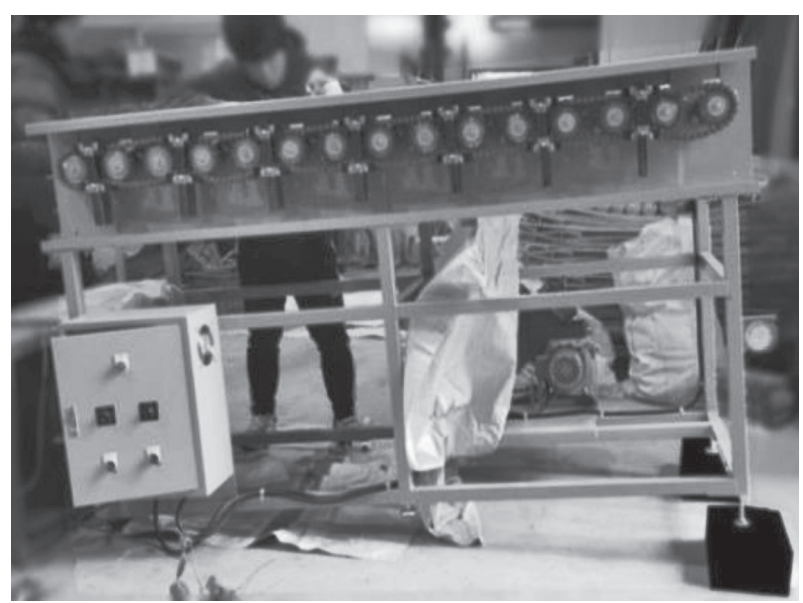

Fig. 1. Experimental bench for the separating part.
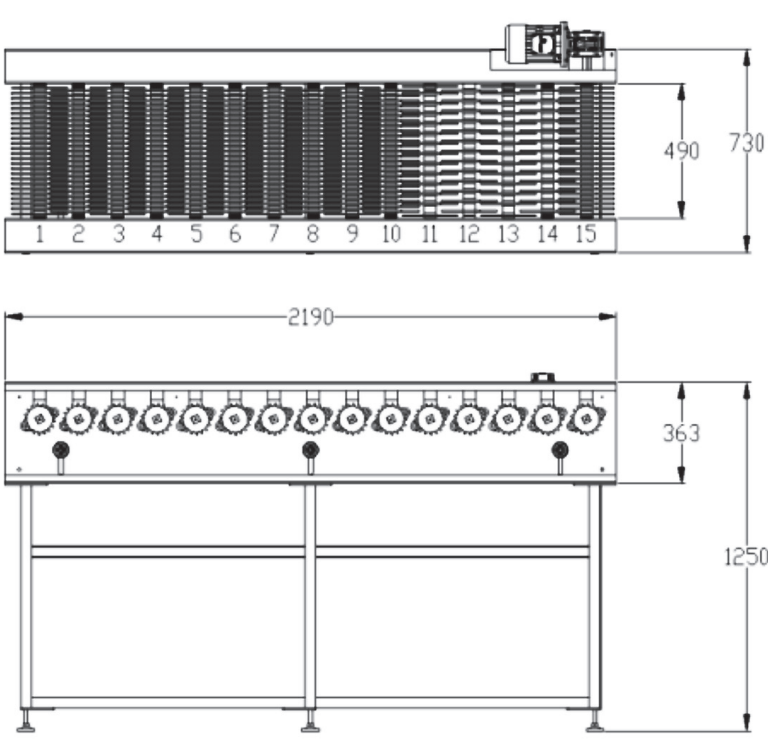

Fig. 2. Specification of the experimental device for the separating part.

Table 1. Specifications of the card

\begin{tabular}{lc}
\hline \multicolumn{1}{c}{ Parameters } & Value \\
\hline Length of card (mm) & 150 \\
Width of card (mm) & 150 \\
Thickness of card (mm) & 4.8 \\
Distance between cards (mm) & 13.2 \\
Distance between shafts (mm) & 140 \\
\hline
\end{tabular}




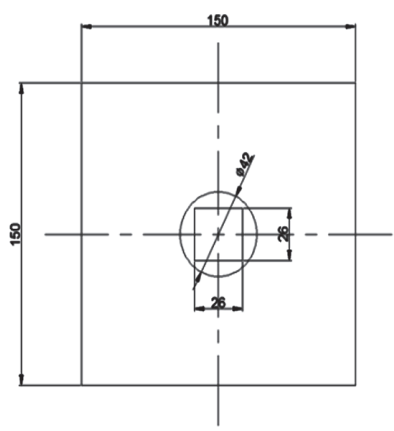

Fig. 3. Shape of the card used in this study.

$11 \sim 14$ th axes, the final stage of the separation part. The slope angle of the card cleaner was adjusted by the pedestal placed under the card cleaner.

25 26 plastic cards were installed on each axis of the card cleaner. Fig. 3 and Table 1 show the shape and specification of the card cleaner.

\section{Physical Properties of Sample Peppers}

The cultivar of the test sample was 'Nokhwang', and it was grown in a plastic greenhouse at Gwangju, Republic of Korea. The sample was transplanted on July 15, 2015 and harvested on March 7, 2016.

Physical properties of the pepper plants and fruits were measured. The properties of 10 randomly selected pepper plants and 30 fruits from the 10 pepper plants were investigated. Fig. 4 shows the measuring positions in the pepper plants and fruits, and Table 2 presents the
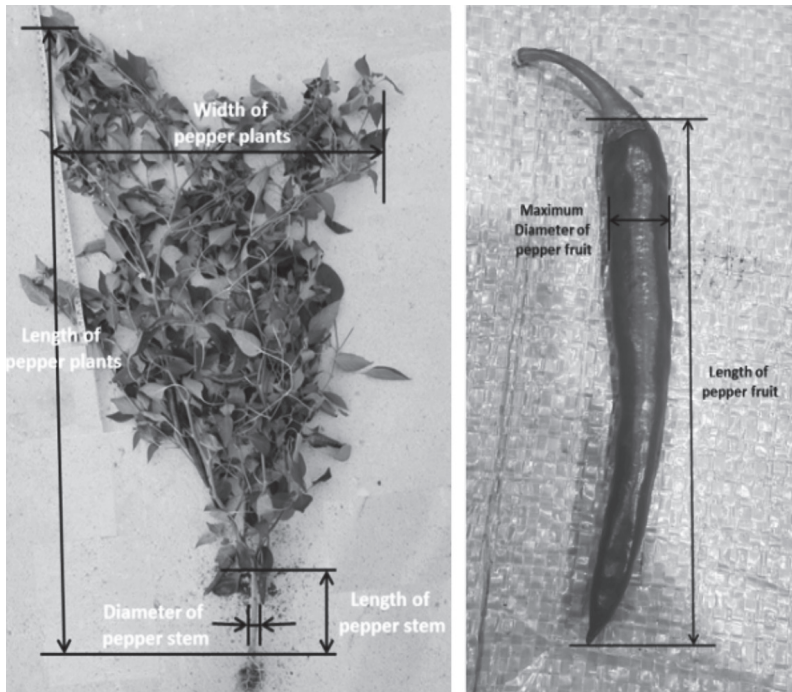

Fig. 4. Measuring positions for the physical properties of the sample peppers.

physical properties of them. The moisture content of branch, leaf, and fruit were measured by oven-dry method $\left(70^{\circ} \mathrm{C}\right.$ for 24 hours $)$. The fruit was cut less than $3 \mathrm{~mm}$ without stem for the moisture content measurement. Table 3 presents the moisture contents of the peppers used in the study.

\section{Condition of Sample Peppers}

The amounts of sample peppers were determined based on the separation work with five pepper plants. Only the peppers passing through the picking head were

Table 2. Physical properties of the sample peppers

\begin{tabular}{cccc}
\hline & Parameters & Average value & Standard deviation \\
\hline \multirow{4}{*}{ Plant } & Length of pepper plant (mm) & 1618 & 97.24 \\
& Width of pepper plant (mm) & 830 & 60.17 \\
& Length of pepper stem (mm) & 209.5 & 32.05 \\
& Diameter of pepper stem (mm) & 15.8 & 3.16 \\
& Length (mm) & 124.77 & 13.68 \\
\multirow{3}{*}{ Fruit } & Max. diameter (mm) & 14.67 & 1.89 \\
& Weight (kg) & 13.34 & 3.22 \\
& Amount (ea/plant) & 85.6 & 8.18 \\
\hline
\end{tabular}

Table 3. Moisture contents of the sample peppers

\begin{tabular}{cccc}
\hline Part & Weight before oven drying (g) & Weight after oven drying (g) & Moisture contents (\%) \\
\hline Fruit & 134.51 & 14.84 & 88.97 \\
Branch & 50.00 & 10.52 & 78.96 \\
Leaf & 50.00 & 10.85 & 78.30 \\
\hline
\end{tabular}

Table 4. Weight and length of sample peppers

\begin{tabular}{ccc}
\hline Pepper weight $(\mathrm{g})$ & Branch weight $(\mathrm{g})$ & Branch length (mm) \\
\hline 2100 & 400 & 200 \\
\hline
\end{tabular}




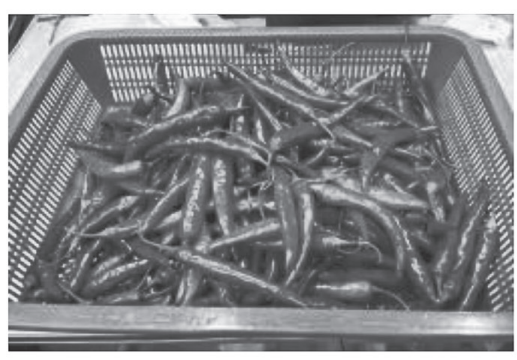

(a) Pepper

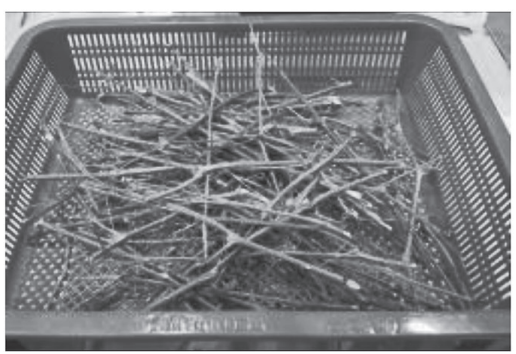

(b) Branch

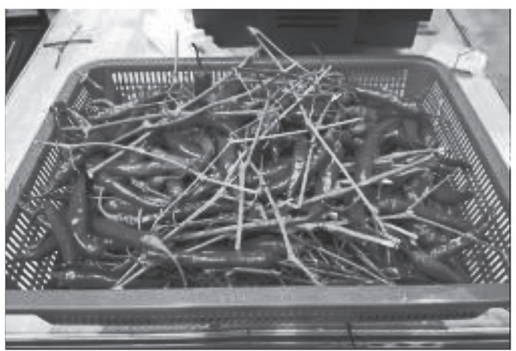

(c) Mixture of pepper and branch

Fig. 5. Samples for the experiment.

used in this study, and $200 \mathrm{~mm}$-length branches were used considering the length range observed in the field measurement (150 250 mm). Leaf-removed plants were prepared to make similar conditions that Ethephon and salt treatment before machine harvesting (Fig. 5 and Table 4).

\section{Parameters}

The separation performance was examined with two types of card arrangement, inline arrangement that used in the USA and staggered arrangement that tried first in this study. Fig. 6 shows each type of card arrangement, and Table 5 presents the distance between the cards in each arrangement.

The experiments were conducted by changing the

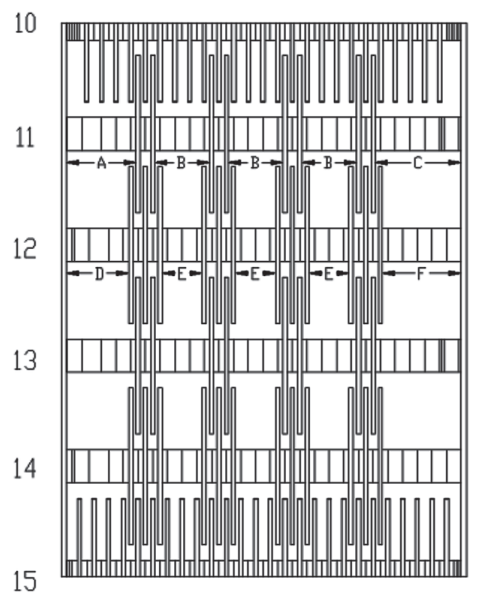

(a) Inline arrangement

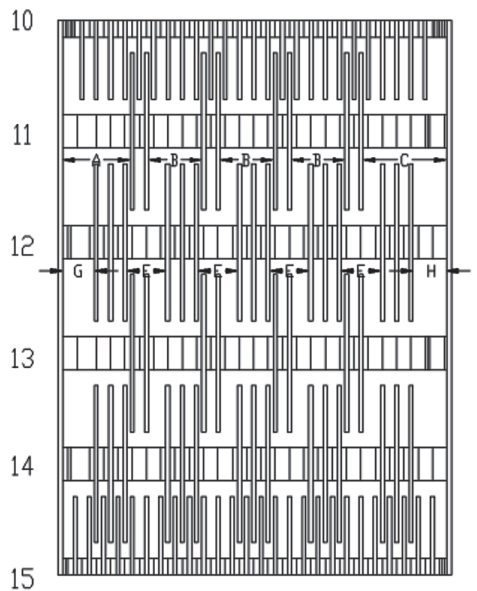

(b) Staggered arrangement

Fig. 6. Distance between the cards in each arrangement.

rotational speed of driving axis and slope angle to investigate the factors that influence the separation performance for each card arrangement. Table 6 presents kind of factors and their magnitude that examined in this study.

Working time of $11.25 \mathrm{sec}$ was used following the results of picking head tests under the conditions of working distance of $2.25 \mathrm{~m}$ (five pepper plants) and working speed of $0.2 \mathrm{~m} / \mathrm{s}$. The tests were repeated three times, and the separation efficiency of peppers and mixing ratio of foreign materials were analyzed with the sample at the collecting box after each test was finished. Fig. 7 presents the position of the collecting box in the experimental bench.

Table 5. Distance between the cards in each arrangement

\begin{tabular}{cccccccc}
\hline $\mathrm{A}(\mathrm{mm})$ & $\mathrm{B}(\mathrm{mm})$ & $\mathrm{C}(\mathrm{mm})$ & $\mathrm{D}(\mathrm{mm})$ & $\mathrm{E}(\mathrm{mm})$ & $\mathrm{F}(\mathrm{mm})$ & $\mathrm{G}(\mathrm{mm})$ & $\mathrm{H}(\mathrm{mm})$ \\
\hline 88.4 & 67.2 & 108.2 & 79.4 & 49.2 & 99.4 & 43.4 & 45.2 \\
\hline
\end{tabular}




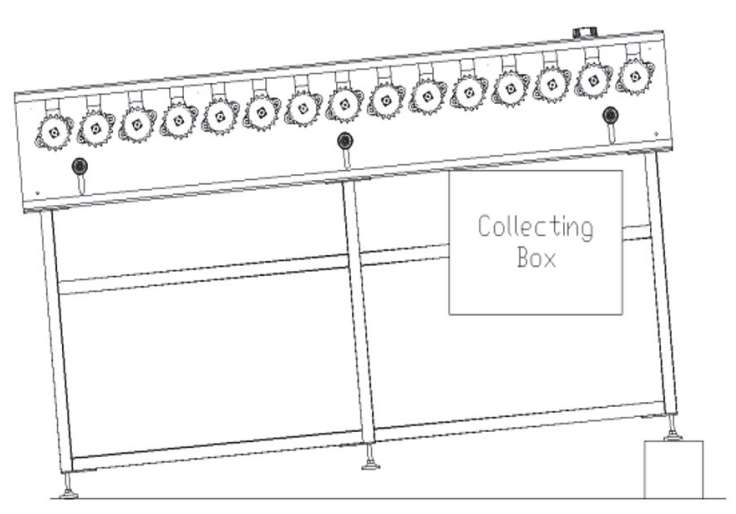

Fig. 7. Position of the collecting box.

Table 6. Experimental factors in this study

\begin{tabular}{lc}
\hline \multicolumn{1}{c}{ Factors } & Values \\
\hline Rotational speed (rpm) & $35,50,65$ \\
Slope angle (degree) & 5,15 \\
Card arrangement & Inline, Staggered \\
\hline
\end{tabular}

\section{Analysis Method}

The separation efficiency of peppers and mixing ratio of foreign materials were examined by measuring the weights of the fruits and foreign materials collected at the collecting box. The separation efficiency of peppers means the ratio of fruits collected at the collecting box to the total amount of peppers supplied to the separation part as represented in equation (1).

$$
D_{\text {sep }}=\frac{P_{c p}}{P_{t p}} \times 100
$$

where, $D_{\text {sep }}$ is the separation efficiency of peppers (\%), $P_{\mathrm{tp}}$ is the total amount of fruits supplied to the separation part (g), $P_{\mathrm{cp}}$ is the amount of peppers supplied to the separation part (g).

The mixing ratio of foreign materials means the ratio of foreign materials collected at the collecting box to the total amount of foreign materials supplied to the separation part as represented in equation (2).

$$
D_{m o f}=\frac{P_{c f}}{P_{t f}} \times 100
$$

where, $D_{\text {mrf }}$ is the mixing ratio of the foreign materials (\%), $P_{\mathrm{tf}}$ is the total amount of foreign materials supplied to the separation part $(\mathrm{g}), P_{\mathrm{cf}}$ is the amount of foreign materials collected at the colleting box (g).

\section{RESULTS AND DISCUSSION}

Table 7 provides the results of the experiments conducted by changing slope angle of the card cleaner and rotational speed of driving axis with two types of card arrangement.

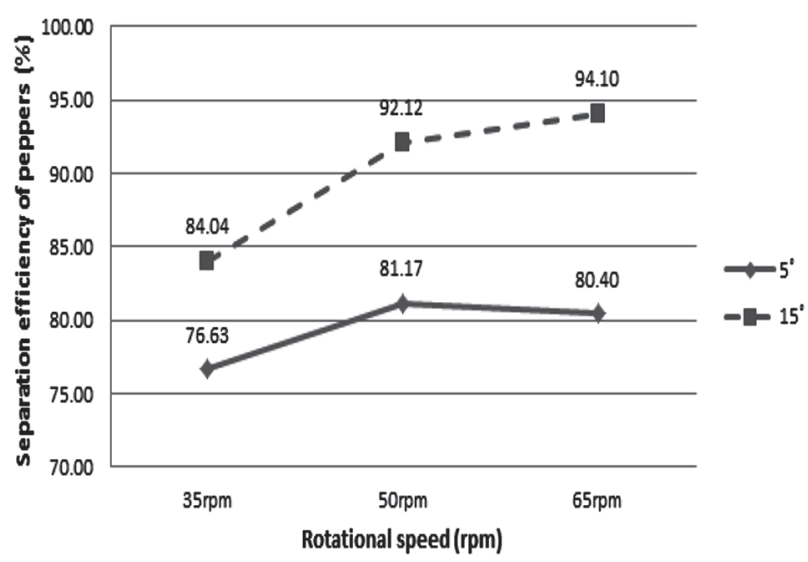

Fig. 8. Results of the separation efficiency of peppers in the inline arrangement.

\section{Separation Efficiency of Peppers in the Inline Arrangement}

Fig. 8 shows the tendency of separation efficiency according to the slope angle and rotational speed of the card cleaner in the inline arrangement. In terms of rotational speed of the card cleaner, there was no significant difference between $50 \mathrm{rpm}$ and $65 \mathrm{rpm}$ in the separation efficiency, but there was significant difference between $35 \mathrm{rpm}$ and 50 or $65 \mathrm{rpm}$. In terms of slope angle of the card cleaner, $15^{\circ}$ showed higher separation efficiency than $5^{\circ}$ by $7.4 \sim 13.7 \%$ in the different rotational speed condition.

According to the results shown in Table 8 (SAS, 1990), the slope angle and rotational speed of the card cleaner influenced the separation efficiency of peppers at a 95\% confidence level. In addition, interactions between slope angle and rotational speed also influenced the separation efficiency of peppers.

\section{Mixing Ratio of Foreign Materials in the Inline Arrangement}

Fig. 9 presents the results of the mixing ratio of foreign materials according to the slope angle and rotational speed of the card cleaner in the inline arrangement. In terms of rotational speed of the card cleaner, the mix-

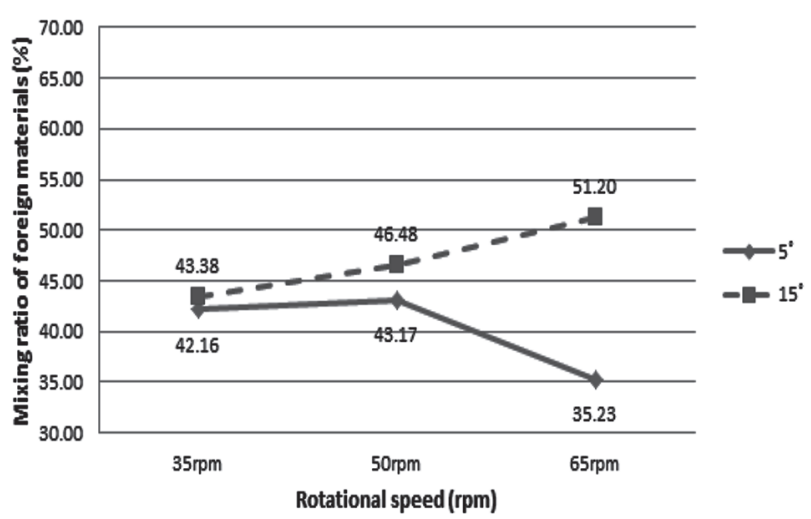

Fig. 9. Results of the mixing ratio of foreign materials in the inline arrangement. 
Table 7. Experimental results

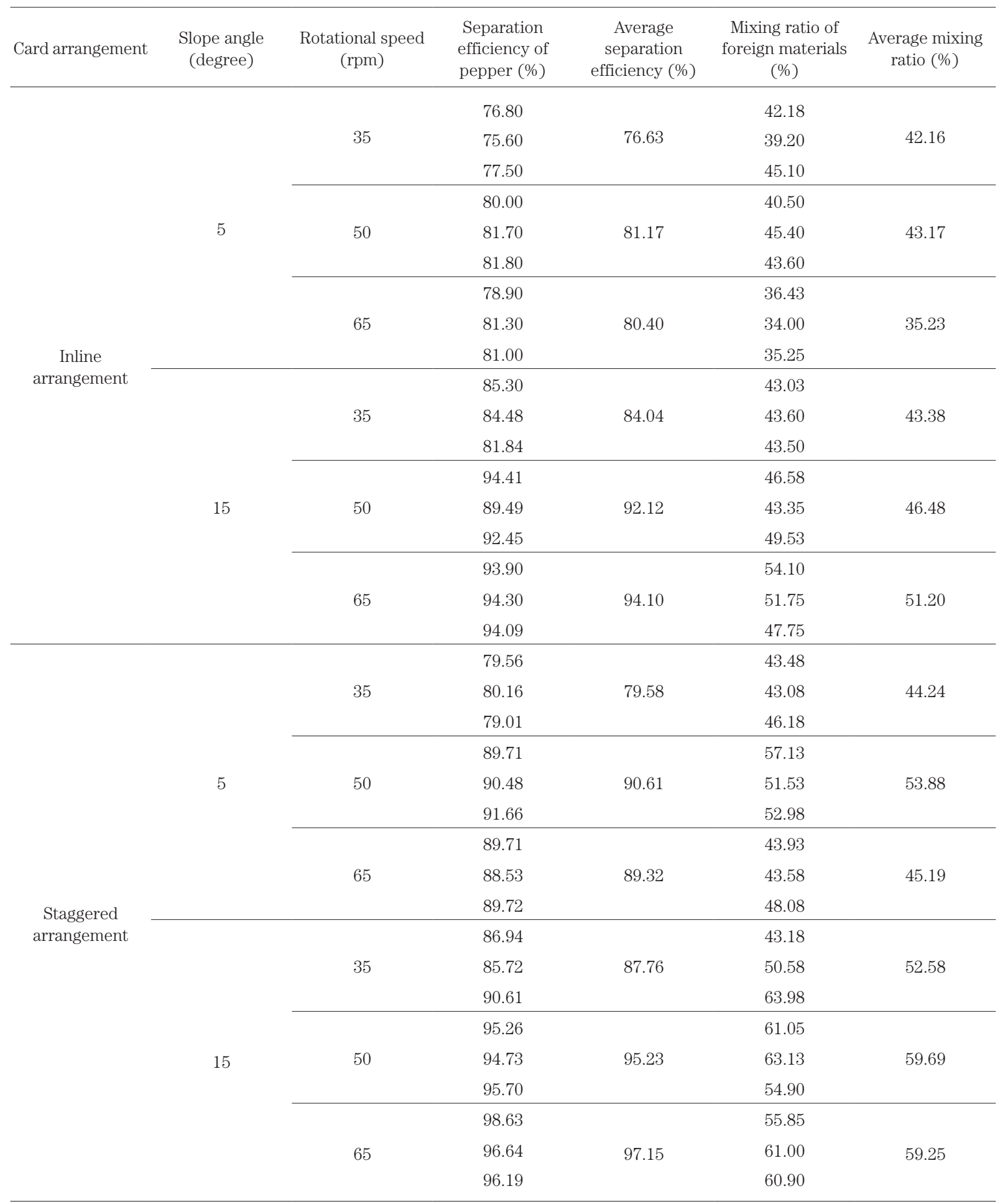

Table 8. Statistical results of the separation efficiency of peppers in the inline arrangement

\begin{tabular}{crcccc}
\hline Source & DF & Anova SS & Mean Square & F Value & $\operatorname{Pr}>$ F \\
\hline Slope angle & 1 & 513.7 & 513.7 & 221.8 & $<.0001$ \\
Rotational speed & 2 & 175.8 & 87.9 & 37.9 & $<.0001$ \\
Angle*Speed & 2 & 29.8 & 14.9 & 6.4 & 0.0126 \\
Error & 12 & 27.8 & 2.3 & & \\
Total & 17 & 747.1 & & & \\
\hline
\end{tabular}


Table 9. Statistical results of the mixing ratio of foreign materials in the inline arrangement

\begin{tabular}{crrrrr}
\hline Source & DF & Anova SS & Mean Square & F Value & Pr $>$ F \\
\hline Slope angle & 1 & 210.3 & 210.3 & 34.8 & $<.0001$ \\
Rotational speed & 2 & 14.1 & 7.0 & 1.2 & 0.3451 \\
Angle*Speed & 2 & 191.1 & 95.6 & 15.8 & 0.0004 \\
Error & 12 & 72.6 & 6.0 & & \\
Total & 17 & 488.1 & & & \\
\hline
\end{tabular}

ing ratio of the foreign materials was lowest at a rotational speed of $65 \mathrm{rpm}$ when the slope angle was $5^{\circ}$ and, and it increased with increasing rotational speed when the slope angle was $15^{\circ}$. The low mixing ratio of foreign materials at $5^{\circ}$ and $65 \mathrm{rpm}$ was caused by the rapid rotation of the card cleaner, which discharged longer foreign materials than fruits not collecting them at the collecting box. In terms of slope angle of the card cleaner, a slope of $5^{\circ}$ showed lower mixing ratio of foreign materials by $1.2 \sim 16 \%$ than a slope of $15^{\circ}$ in the different rotational speed condition.

According to the results shown in Table 9 (SAS, 1990), the slope angle of the card cleaner influenced the mixing ratio of foreign materials at a 95\% confidence level. However, the rotational speed of the card cleaner did not influence the mixing ratio of foreign materials because no significant difference was observed between rotational speed and mixing ratio of foreign materials. In addition, interactions between slope angle and rotational speed influenced the mixing ratio of foreign materials.

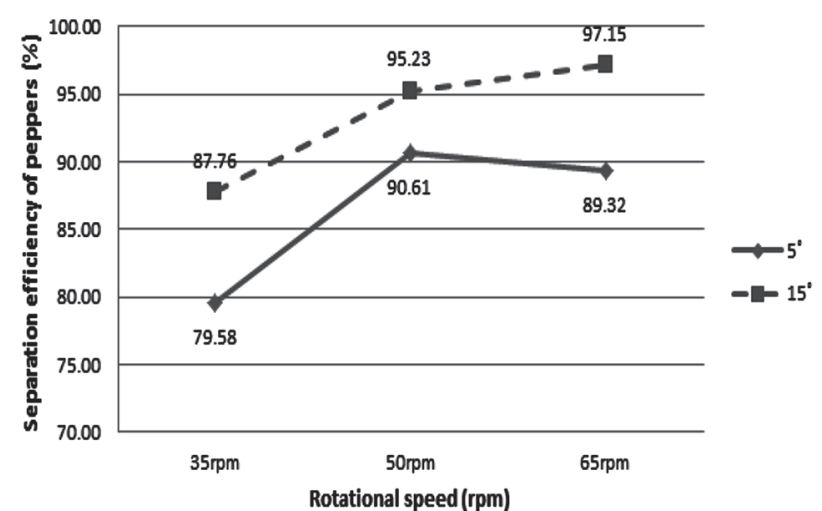

Fig. 10. Results of the separation efficiency of peppers in the staggered arrangement.

\section{Results Summary for the Inline Arrangement}

In the inline arrangement, the separation efficiency of peppers was influenced by both slope angle and rotational speed of the card cleaner, but mixing ratio of foreign materials was influenced by only the slope angle of the card cleaner. The separation efficiency of peppers was highest at $15^{\circ}$ and $65 \mathrm{rpm}$, and the mixing ratio of foreign materials was higher at $15^{\circ}$ than $5^{\circ}$. When the slope angle was increased, fruits and foreign materials stayed longer on the card cleaner which resulted in increasing the amount of fruits and foreign materials collected at the collecting box. In addition, there was no significant difference in the separation performance at the rate of over $50 \mathrm{rpm}$.

\section{Separation Efficiency of Peppers in the Staggered Arrangement}

Fig. 10 shows the results of the separation efficiency of peppers according to the slope angle and rotational speed of the card cleaner in the staggered arrangement.

In terms of rotational speed of the card cleaner, there was no significant difference between $50 \mathrm{rpm}$ and $65 \mathrm{rpm}$ in the separation efficiency, but there was significant difference between $35 \mathrm{rpm}$ and 50 or $65 \mathrm{rpm}$. In terms of slope angle of the card cleaner, $15^{\circ}$ showed higher separation efficiency than $5^{\circ}$ by $4.6 \sim 8.2 \%$ in the different rotational speed condition.

According to the results shown in Table 10 (SAS, 1990), the slope angle and rotational speed of the card cleaner influenced the separation efficiency of peppers at a $95 \%$ confidence level. In addition, interactions between slope angle and rotational speed did not influence the separation efficiency of peppers.

\section{Mixing Ratio of Foreign Materials in the Staggered Arrangement}

Fig. 11 presents the results of the mixing ratio of foreign materials according to the slope angle and rota-

Table 10. Statistical results of the separation efficiency of peppers in the staggered arrangement

\begin{tabular}{crcccc}
\hline Source & DF & Anova SS & Mean Square & F Value & Pr $>$ F \\
\hline Slope angle & 1 & 212.7 & 212.7 & 125.6 & $<.0001$ \\
Rotational speed & 2 & 354.7 & 177.4 & 104.7 & $<.0001$ \\
Angle*Speed & 2 & 11.6 & 5.8 & 1.7 & 0.0665 \\
Error & 12 & 20.3 & & & \\
Total & 17 & 599.4 & & & \\
\hline
\end{tabular}


tional speed of the card cleaner in the staggered arrangement. In terms of rotational speed of the card cleaner, the mixing ratio of the foreign materials was lowest at the rotational speed of $35 \mathrm{rpm}$ when the slope angles were $5^{\circ}$. In terms of slope angle of the card cleaner, a slope of $5^{\circ}$ showed lower mixing ratio of foreign materials by $5.8 \sim 14.1 \%$ than a slope of $15^{\circ}$ in the different rotational speed condition.

According to the results shown in Table 11 (SAS, 1990), the slope angle and rotational speed of the card cleaner influenced the mixing ratio of foreign materials at a $95 \%$ confidence level. In addition, interactions between slope angle and rotational speed did not influence the mixing ratio of foreign materials.

\section{Results Summary for the Staggered Arrangement}

In the staggered arrangement, the separation efficiency of peppers and mixing ratio of foreign materials were influenced by both slope angle and rotational speed of the card cleaner. The separation efficiency of peppers was highest at $15^{\circ}$ and $65 \mathrm{rpm}$, and the mixing ratio of foreign materials was lower at $5^{\circ}$ than $15^{\circ}$.

When the slope angle was increased, fruits and foreign materials stayed longer on the card cleaner which resulted in increasing the amount of fruits and foreign materials collected at the collecting box. In addition, there was no significant difference in the separation performance at the rate of over $50 \mathrm{rpm}$.

\section{CONCLUSIONS}

This study conducted experiment for a card cleaner type separation device to analyze the separation perfor-

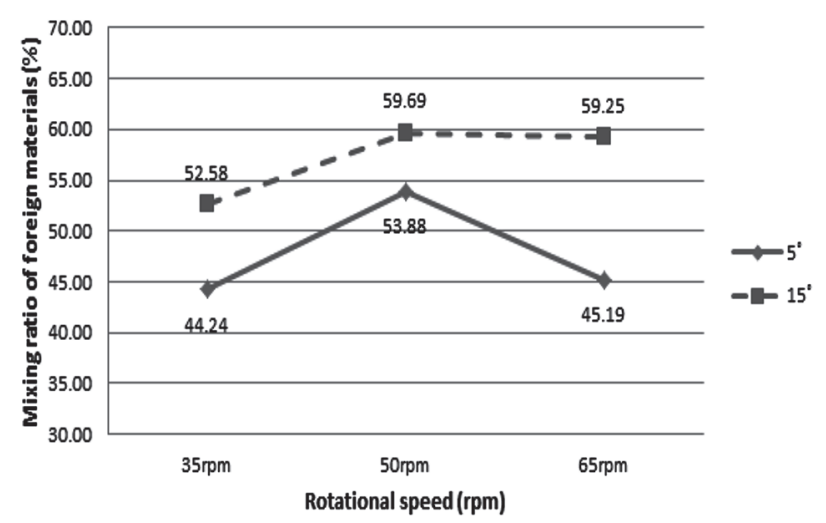

Fig. 11. Results of the mixing ratio of foreign materials in the staggered arrangement. mance according to the influence factors such as card arrangement, slope angle, and rotational speed of the card cleaner.

When the slope angle was increased, the separation efficiency and mixing ratio of foreign materials also increased in the two types of card arrangement, i.e. inline arrangement and staggered arrangement. The separation performance is optimized when separation efficiency is increased and mixing ratio of foreign materials is minimized. In the slope angle of $5^{\circ}$, the highest separation efficiency was obtained in the staggered arrangement at rotational speed of $50 \mathrm{rpm}$ (separation efficiency of $90.61 \%)$. However, in this condition, the mixing ratio of foreign materials was high as 53.88\%, which requires additional separation processes. In the slope angle of $15^{\circ}$, the high separation efficiency was obtained inline arrangement at rotational speed of $50 \mathrm{rpm}$ (separation efficiency of $92.12 \%$ ). The mixing ratio of foreign materials was relatively low (46.48\%) in this condition. Thus, the results of this study suggested that self-propelled pepper harvesters should be designed to have the inline arrangement card cleaner with a slope angle of $15^{\circ}$.

\section{ACKNOWLEDGEMENT}

This study was supported by Korea Institute of Planning and Evaluation for Technology in Food, Agriculture, Forestry and Fisheries (IPET) through "Advanced Production Technology Development Program", funded by Ministry of Agriculture, Food and Rural Affairs (MAFRA)(314035-3)

\section{REFERENCES}

Choi, Y. 2006 Development of Machine Harvester for Pepper. PhD dissertation, Chonnam National University, Gwangju, Korea (in Korean with English abstract)

Eaton, F. E. and C. Wilson. 2005 Refinement and Testing of Mechanical Cleaners for Red Chile. New Mexico State University Chile Task Force Report 22, NM

FAOSTAT. 2012 Food and agriculture organization of the United Nations. Available at: http://faostat.fao.org.

Herbon, R., G. Abernathy and E. Hughs. 2006 Design and Development of a Prototype Mechanical Gap Sorter for Mechanically Harvested Red Chile. New Mexico State University Chile Task Force Report 25, NM

Hong, J. T., K. H. Jo, N. H. Jo, J. K. Hong, Y. Choi, S. Y. Shin and C. K. Choi. 2006 Study on Integrated Mechanization System for Harvest and Postharvest Operation of Once-over-harvest Pepper. Symposium of Korean Society for Agricultural Machinery, 11(2): 184-189 (in Korean with English abstract)

Kong, L. J., Y. C. Chen, L. Ma and Y. L. Duan. 2013 Research and

Table 11. Statistical results of the mixing ratio of foreign materials in the staggered arrangement

\begin{tabular}{crcccc}
\hline Source & DF & Anova SS & Mean Square & F Value & Pr $>$ F \\
\hline Slope angle & 1 & 397.6 & 397.6 & 15.3 & 0.0021 \\
Rotational speed & 2 & 210.9 & 105.5 & 4.1 & 0.0449 \\
Angle* Speed & 2 & 53.5 & 26.7 & 1.0 & 0.3864 \\
Error & 12 & 311.4 & 25.9 & & \\
Total & 17 & 973.4 & & & \\
\hline
\end{tabular}


design of line pepper cleaning and separating device, based on star wheel and airflow. Journal of Chinese Agricultural Mechanization, 34(2): 102-105

KOSTAT. 2014 Crop production statistics. Korea National Statistical Office. Available at: http://kostat.go.kr.

Marshall, D. E. 1984 Mechanized pepper harvesting and trash removal. ASAE Pub. No. 5-84: 276-283, St. Joseph, MI 48824

SAS. SAS User's Guide. 1990. Statistics. Ver. 9.3 Cary, NC: SAS Institute, Inc.

Wolf, I. and Y. Alper. 1984 Mechanization of Paprika harvest.
ASAE Pub. No. 5-84: 265-275, St. Joseph, MI 49085

Author Contributions: Y. Jo designed the study, performed the experiments, analyzed the data and wrote the paper. Y. Kang designed the study and provided facilities and resources. J. Nam performed the statistical analysis. J. Choe, E. Inoue and T. Okayasu participated in the design of the study. D. Kim designed the study, wrote the paper and supervised the work. All authors assisted in editing of the manuscript and approved the final version. 